\title{
Esforços da Pós-graduação em políticas públicas e desenvolvimento local para a Interiorização
}

\section{Post-graduate efforts in public policies and local development for interiorization}

\author{
Maristela Dalbello-Araujo ${ }^{a}$ \\ (D) https://orcid.org/0000-0002-9950-3358 \\ Janice Gusmão F. Andrade ${ }^{a}$ \\ (D) https://orcid.org/0000-0003-3056-9209 \\ Valmin Ramos-Silva ${ }^{a}$ \\ (D) https://orcid.org/0000-0003-1574-0266
}

\begin{abstract}
The contributions of scientific research to society can be measured by indicators and the social insertion of the programs is one of them. In this article we list and discuss the particularities of the social impact of the Postgraduate Program in Public Policies and Local Development at the School of Science of Santa Casa de Misericórdia de Vitória, highlighting its important role in the dissemination of knowledge, especially in the area of health for the state of Espírito Santo.
\end{abstract}

Keywords: Graduate education. Education, continuing. Local development. Social Work. 


\section{Introdução}

Lei de Diretrizes e Bases da Educação Nacional, instituída em 1961 e aprovada em 1965 (Brasil, 1996), surgiu em um contexto político de promoção do desenvolvimento econômico do país, o que demandava a formação de recursos humanos qualificados com vistas a atender suas principais demandas, tais como a necessidade de mão de obra especializada para preencher os novos empregos criados pelo desenvolvimento e a necessidade de cientistas, pesquisadores e técnicos aptos a desenvolver pesquisas (Scochi et al., 2013).

A Reforma Universitária de 1968 modernizou uma parte significativa das universidades federais e algumas instituições estaduais e confessionais que incorporaram gradualmente as modificações acadêmicas propostas pela reforma. Esse contexto propiciou condições para a criação do tripé que busca articular as atividades de ensino, pesquisa e extensão, além de criar uma política nacional de pós-graduação que tem seu desempenho acompanhado e avaliado pela Coordenação de Aperfeiçoamento de Pessoal de Nível Superior (Brasil, 2017).

Dessa forma, a pós-graduação tornou-se instrumento fundamental para a inovação do ensino superior no país. Um dos pilares que demonstram essa força é o Programa de Iniciação Científica e Tecnológica, voltado para o desenvolvimento do pensamento científico e iniciação à pesquisa de estudantes de graduação do ensino superior, contribuindo para qualificar e reduzir o tempo médio de permanência de estudantes na pós-graduação, estimulando, por consequência, a formação de novos pesquisadores (Martins, 2009).

Segundo Silva e Carvalho (2007), a partir dos anos 1980 houve um avanço significativo no campo da pós-graduação stricto sensu em diversas áreas e particularmente no Serviço Social, no âmbito das ciências sociais aplicadas. Esse marco significa que a área, a partir de então, assume o desafio de produzir seus próprios conhecimentos e atesta o grande esforço para a formação de professores e pesquisadores, contribuindo, sobremaneira, para a consolidação das ciências sociais no Brasil. 
Assim, inferindo que a universidade e, por conseguinte, a pós-graduação devem ser compreendidas no movimento histórico das mudanças socioeconômicas e políticas da sociedade, é preciso também ressaltar o enorme desafio que os participantes desse processo têm enfrentado devido à mercantilização do ensino. Nesse sentido, a onda neoliberal que assola os países da América Latina e o mundo transformou o ensino em mercadoria produzida em larga escala, principalmente a graduação e a pós-graduação, que passa a ser adquirida por quem pode pagar, e por vezes alheia ao que o país realmente necessita, já que se comporta de acordo com os parâmetros do mercado regido pela oferta e pela procura.

Nesse ambiente de concorrência e ranqueamento entre pesquisadores e instituições de ensino, as ciências humanas e sociais têm que provar seu valor em meio a uma onda de demanda por eficiência, lucratividade e resultados, e são chamadas a dar respostas às expressões da questão social, sequelas das mudanças sociais e econômicas (Trein e Rodrigues, 2011). Além disso, o ensino universitário do Brasil vem sofrendo inúmeros ataques, principalmente nos últimos dois anos, haja vista a entrada de governos conservadores na direção do país (Lima e Hypolito, 2019).

Entretanto, mais do que discutir as mazelas pelas quais passam professores e pesquisadores, é preciso resgatar o valor do uso social da produção científica. Sabe-se que as contribuições da pesquisa científica à sociedade são mediadas por processos políticos, culturais e sociais amplos. No entanto, alguns elementos podem ser considerados indicadores de quais são essas contribuições, e entendemos que a inserção social da universidade e particularmente dos programas de pós-graduação convêm a tal finalidade (Marziale e Mendes, 2007).

Assim, sabedores da situação delicada pela qual passa o ensino universitário, de modo geral, e a pós-graduação, especificamente, e movidos pela vontade de escrutinar nossos fazeres e caminhar no sentido do aperfeiçoamento teórico, mas também na intenção de colaborar para a resolução dos problemas que enfrentam nosso país, nos dedicamos a refletir sobre o papel da inserção social da pós-graduação. 


\section{Programas de pós-graduação no Espírito Santo}

O primeiro curso em nível de mestrado do estado iniciou-se em 1978, na área de Educação, e a expansão da pós-graduação stricto sensu acompanhou o movimento do restante do país, com predominância das universidades públicas. Atualmente, o Espírito Santo conta com 110 cursos, treze ofertados em faculdade privadas e os demais pela universidade e instituto federal.

No âmbito da área de avaliação do Serviço Social encontram-se dois programas de mestrado, um em Políticas Sociais instalado na Universidade Federal do Espírito Santo (Ufes) e o Programa de Pós-Graduação em Políticas Públicas e Desenvolvimento Local (PPGPPDL) da Escola Superior de Ciências da Santa Casa de Misericórdia de Vitória (Emescam), entidade de caráter filantrópico, sem fins lucrativos. Ambos têm corpo docente e discente de caráter interdisciplinar. Entretanto, devido à característica de mais de trinta anos de formação na área de Ciências da Saúde, a grande maioria das pesquisas oriundas do PPGPPDL versa sobre as políticas desse setor.

De acordo com a coordenação da área do Serviço Social, no âmbito das inovações, transformações e propostas, as estratégias de formação e intervenção na realidade se efetivam na atuação profissional qualificada, nas políticas públicas e sociais e, ainda, na articulação de organismos da sociedade civil para fortalecer e ampliar direitos (Brasil, 2017).

É inegável o papel desempenhado pelas pesquisas oriundas desses programas e a validade da inserção social que deles se depreende. Tal inserção se dá pelo subsídio à economia do estado, que cresceu exponencialmente a partir da segunda metade do século XX, com atividades ligadas ao comércio local, agricultura e indústria, incluindo o comércio exterior e seus problemas associados ao meio ambiente e às diversas expressões da questão social que traduzem as contradições do desenvolvimento da sociedade capitalista. 


\section{Inserção social do PPGPPDL}

Um dos quesitos da avaliação da pós-graduação tem por objetivo identificar como os mestres e doutores, bem como suas pesquisas, interferem na resolução de problemas que atingem a sociedade. Muitos dos pesquisadores afirmam que se faz necessário discutir a contribuição efetiva de tais programas para o desenvolvimento social e econômico do país. Assim, acreditam que a inserção social e a avaliação do impacto socioeconômico dos programas de pós-graduação devam ser objeto de análise, não apenas por aqueles que deles fazem parte, mas também pela sociedade. Dessa forma, seguiremos em análise pelos quesitos propostos pela Coordenação de Aperfeiçoamento de Pessoal de Nível Superior (Capes).

\section{Impacto educacional}

Considerando a educação como agente de transformação e emancipação humana, mediadora da função crítica, na luta por uma sociedade mais justa, temos dirigido ações para a escola pública, ao implementar projetos envolvendo estudantes e professores no debate e na construção de ações propositivas sobre discriminação racial, violação de direitos humanos, formas de acesso ao ensino superior e inclusão de estudantes com necessidades específicas no âmbito escolar.

No que tange ao impacto educacional relacionado aos cursos de graduação da Emescam, verificamos que muitos estudantes de Medicina, Fisioterapia, Enfermagem e Serviço Social fazem parte dos grupos de pesquisa constituídos no âmbito do mestrado. Tal inserção aproxima os estudantes dos projetos que vêm sendo desenvolvidos, ao mesmo tempo em que os instiga a dar prosseguimento aos seus estudos em nível de mestrado, além de trazer uma atualização constante de temáticas, conteúdos e bibliografias.

No ano de 2019, mais de trinta graduandos estavam inseridos nesses grupos, parte deles no Programa Institucional de Bolsas de Iniciação 
Científica (Pibic) e no Programa Institucional de Voluntários de Iniciação Científica (Pivic). Esses programas são coordenados por um dos professores do PPGPPDL, o que facilita ainda mais o intercâmbio entre a graduação e a pós-graduação na instituição.

Outra maneira de inserção social do programa dar-se-á pela participação dos docentes na organização de eventos científicos que discutem a conjuntura histórica e inserção das ciências humanas, com foco na área do Serviço Social, envolvendo egressos, mestrandos, graduandos dos cursos das Ciências da Saúde e Sociais e a comunidade científica da região, no sentido de fortalecer a relação indivíduo-sociedade, como questão fundante das ciências sociais. 0 temário desses eventos contribuiu para balizar tendências de explicações para questões emergentes de natureza social e histórica, com perspectivas de reflexão sobre as interfaces e interlocuções entre as diversas ciências (Gomes e Goldenberg, 2003).

Outrossim, alguns dos docentes participam de conselhos municipais, estaduais e nacionais como representantes, o que contribui com a necessária inserção do tema das políticas públicas no escopo dos cursos de graduação. Além disso, existe atuação docente na avaliação dos cursos de graduação da área da saúde, cujas revisões das diretrizes curriculares vêm sendo acompanhadas de perto por representantes do Controle Social da Saúde em sua atribuição de zelar pela adequação dos cursos à política de saúde do país.

\section{Formação de recursos humanos para a administração pública}

A acumulação flexível e desregulamentada que adentra a década de 1980 gerou desafios para a garantia de investimento na formação e no aprimoramento de recursos humanos (Mello e Amâncio Filho, 2010). Nesse sentido, os egressos do PPGPPDL vêm contribuindo sobremaneira na gestão pública, à frente das secretarias municipal e estadual. Também atuam como convidados para capacitar servidores públicos e como 
mentores ou consultores na capacitação de áreas técnicas, em especial na saúde, não somente na capital do Espírito Santo, mas também nos municípios do interior.

As contribuições do mestrado para o conhecimento e a intervenção na realidade local têm resultado no financiamento de projetos de pesquisa pela Fundação de Amparo à Pesquisa do Estado do Espírito Santo (Fapes), que visam diretamente o aprimoramento de políticas de gestão de dois setores cruciais da política de saúde: a urgência e a emergência, por meio do projeto "Mapeamento dos acidentes de transportes terrestres e outras causas externas na população assistida pelo serviço de atendimento móvel de urgência - Samu" (Fapes, 2018). Dele participam professores da Ufes e da Universidade Federal de Uberlândia (UFU), graduandos em Medicina, Enfermagem, Fisioterapia, Geografia e Engenharia, além de profissionais da Rede de Urgência e Emergência do Espírito Santo.

As temáticas abordadas nas dissertações, algumas delas já publicadas em formato de livro, artigos científicos e trabalhos apresentados em eventos científicos nacionais e internacionais, visam melhorar as ações que são a materialização das políticas públicas, especialmente aquelas de maior impacto para o Espírito Santo. São abordadas ampla variedade de políticas, a saber: Políticas de Saúde, Política Pública de Assistência Social, Enfrentamento à Violência contra as Mulheres, Política Nacional de Mobilidade Urbana, Gestão Pública, Transparência e Controle Social, Seguridade Social, Política de Promoção da Igualdade Racial, de Atenção à Pessoa Idosa, dentre outras políticas públicas e sociais.

Mais de 30,0\% dos atuais mestrandos recebem bolsa do município de Presidente Kennedy (ES), indicando um possível reconhecimento do resultado dessa inserção e pelo reconhecimento social do mestrado como espaço de formação de recursos humanos em políticas públicas e na inserção dos egressos em postos de gestão no Espírito Santo e em outros estados.

Outro reconhecimento público da importância do PPGPPDL para a região foi a homenagem prestada pela Câmara de Vereadores da capital e 
da Assembleia Legislativa do estado, por ocasião dos dez anos de criação do mestrado. Destacam-se como relevantes as parcerias de formação em políticas públicas e gestão pública, voltadas para o desenvolvimento local, com a prefeitura de Presidente Kennedy, com a Secretaria de Estado da Saúde e a Secretaria de Ciência e Tecnologia do Estado do Espírito Santo.

\section{Formação da sociedade civil para o aprimoramento da gestão pública e desenvolvimento cultural}

A qualidade e a efetividade são novas dinâmicas de gestão para o cumprimento do papel institucional que é feito pelo controle social, por meio da sociedade civil e de agentes sociais. No entanto, existem evidências de deficiências e fragilidades nas diversas formas de controle social no que se refere à organização pública municipal (Silva, 2014). Para fortalecer essa ação, o PPGPPDL protagonizou a formação de conselheiros municipais na área do trabalho, direitos humanos, igualdade racial e de gênero. É importante ressaltar que um dos egressos do programa e bolsista da instituição é candidato à presidência da República de Guiné-Bissau, África.

\section{Disseminação dos produtos gerados para o desenvolvimento local}

Quanto à contribuição do mestrado no que diz respeito ao impacto tecnológico/econômico e disseminação de técnicas, destacam-se ações que visam o desenvolvimento sustentável, especialmente no manejo de agricultura, ponto forte no Espírito Santo. Docentes realizam parcerias para a formação de recursos humanos na área de gestão e execução de controle sobre o meio ambiente e desenvolvimento das comunidades rurais.

O Espírito Santo tem forte tradição agropecuária e vem se destacando na última década também no agroturismo, fonte de renda e fixação 
do jovem no campo. Tais parcerias também ocorrem na área da saúde, visto que vários dos docentes do programa são aposentados ou têm vínculos ativos com o serviço público e a expertise adquirida associada ao reconhecimento acadêmico, o que estimula o convite para desenvolver avaliações de programas específicos incluindo a construção ou avaliação de protocolos interdisciplinares de atenção à saúde.

\section{Intercâmbios e cooperação com outros programas}

Mesmo não sendo um quesito obrigatório para os programas de mestrado com nota três, houve discussões com os docentes e um esforço para a participação em parceria com o Programa de Pós-Graduação em Serviço Social da PUCRS (Porto Alegre, RS) e Centre d'Économie de Université Paris Nord (CEPN) da Université Paris XIII (França). Existe, também, desde 2009, um projeto em cooperação técnica com a Agência Internacional de Energia Atômica (Iaea), no qual são realizados estudos multicêntricos com a participação de quinze países da América Latina e do Caribe para avaliar a dupla carga de má nutrição em crianças e adolescentes e sua interface com as políticas de saúde.

\section{Considerações finais}

A universidade brasileira vem tematizando, de longa data, qual a sua finalidade social em meio ao conflito entre capital e trabalho. Mesmo que os atuais membros dos programas de mestrado e doutorado reconheçam a urgência de que o quesito da inserção social seja considerado relevante, há um longo caminho a ser percorrido, haja vista que é o aumento da produção científica e sua divulgação em periódicos qualificados que têm auferido o respeito dos pares e da comunidade científica em geral, garantido os financiamentos e a classificação dos programas.

É sabido que o acirramento da competição e o ranqueamento entre os programas por vezes oblitera a visão e coloca em segundo plano o 
real papel da universidade, que é contribuir, por meio das pesquisas e do conhecimento científico produzido, para a transformação da realidade que nos cerca e sob a qual nos debruçamos em análises. Por isso mesmo, é louvável que a avaliação de área atribua grande valor a esse quesito e é de fundamental importância que analisemos as finalidades das nossas pesquisas e a contribuição efetiva que vimos dando para o desenvolvimento sustentável do nosso país.

Esta foi a motivação deste apanhado, e pudemos constatar que mesmo em meio a dificuldades financeiras e institucionais, um grupo aguerrido de pesquisadores continua firme no propósito de contribuir para o desenvolvimento do Espírito Santo por meio do seu fazer cotidiano, que se traduz na formação de pesquisadores, na qualificação de docentes, recursos humanos para a gestão e produção de conhecimento científico em políticas públicas.

\section{Referências}

BRASIL. Lei no 9.394, de 20 de dezembro de 1996. Estabelece as diretrizes e bases da educação nacional. Disponível em: http://www.planalto.gov.br/ccivil_03/leis/19394.htm. Acesso em: 10 fev. 2020.

BRASIL. Ministério da Educação. Relatório da avaliação quadrienal 2017. Disponível em: http://capes.gov.br/images/documentos/Relatorios_quadrienal_2017/20122017Educacao_relatorio-de-avaliacao-quadrienal-2017_final.pdf. Acesso em: 10 fev. 2019.

FAPES (Fundação de Amparo à Pesquisa e Inovação do Espírito Santo). Chamada pública Fapes/CNPq/Decit-SCTIE-MS/SESA nº3/2018. Programa de pesquisa para o SUS: gestão compartilhada em saúde - PPSUS. Processo Fapes n 80784070. Disponível em: https:// fapes.es.gov.br/Media/fapes/Importacao/Arquivos/EditaisAbertos/Edital_FAPES-CNPqDecit-MS-SESA_PPSUS_03-2018_08mar2018.pdf. Acesso em: 10 fev. 2019.

GOMES, M. H. A.; GOLDENBERG, P. Interfaces e interlocuções: os congressos de ciências sociais em saúde. Ciência e Saúde Coletiva, Rio de Janeiro, v. 8, n. 1, p. 251-264, 2003.

LIMA, I. G.; HYPOLITO, Á. M. A expansão do neoconservadorismo na educação brasileira. Educação e Pesquisa, São Paulo, v. 45. e190901, ago. 2019.

MARTINS, C. B. A reforma universitária de 1968 e a abertura para o ensino superior privado no Brasil. Educação \& Sociedade, Campinas, v. 30, n. 106, p. 15-35, jan./abr. 2009. 
MARZIALE, M. H. P.; MENDES, I. A. C. A inserção social da pós-graduação em enfermagem. Revista Latino-Americana de Enfermagem, Ribeirão Preto, v. 15, n. 5, p. 883-884, set./ out. 2007.

MELLO, M. L. B. C.; AMÂNCIO FILHO, A. A gestão de recursos humanos em uma instituição pública brasileira de ciência e tecnologia em saúde: o caso Fiocruz. Revista de Administração Pública, Rio de Janeiro, v. 44, n. 3, p. 613-636, maio/jun. 2010.

SCOCHI, C. G. S. et al. Pós-graduação stricto sensu em Enfermagem no Brasil: avanços e perspectivas. Revista Brasileira de Enfermagem, Brasília, v. 66, n. esp, p. 80-89, set. 2013.

SILVA, M. O.; CARVALHO, D. B. B. A pós-graduação e a produção de conhecimento no Serviço Social brasileiro. Revista Brasileira de Pós-Graduação, Brasília, v. 4, n. 8, p. 11, 2007.

SILVA, F. K. S. Controle social: participação da sociedade civil na gestão pública com perspectiva para o desenvolvimento local. 2014. 119 f. Dissertação (Mestrado em Desenvolvimento Regional) — Universidade Estadual da Paraíba, Campina Grande, 2014.

TREIN, E.; RODRIGUES, J. O mal-estar na academia: produtivismo científico, o fetichismo do conhecimento-mercadoria. Revista Brasileira de Educação, Rio de Janeiro, v. 16, n. 48, p. 769-792, set./dez. 2011.

\section{Sobre os autores}

Maristela Dalbello-Araujo - Docente do Programa de Pós-Graduação em Políticas Públicas e Desenvolvimento Local.

E-mail: dalbello.araujo@gmail.com

Janice Gusmão F. Andrade - Assistente social, doutora em Serviço Social, docente do Programa de Pós-Graduação em Políticas Públicas e Desenvolvimento Local.

E-mail: janice.andrade@hotmail.com

Valmin Ramos-Silva - Docente do Programa de Pós-Graduação em Políticas Públicas e Desenvolvimento Local.

E-mail: valmin.ramos@emescam.br 